\title{
ABORDAGEM COMUNICATIVA, ARGUMENTAĈ̣̃O E OBJETIVOS DIDÁTICOS: UM EPISÓDIO DE SALA DE AULA DE FÍSICA GERENCIADO POR UM ESTAGIÁRIO'
}

\author{
Rodrigo Drumond Vieira* \\ Silvania Sousa do Nascimento**
}

RESUMO: Neste trabalho, apresentamos análises articuladas de um episódio de regência em sala de aula de física do ensino médio e da sua utilização como instrumento formador em uma disciplina de Prática de Ensino de Física. O objetivo principal é discutir, pelas articulações das análises, as relações, no discurso, dos elementos da tríade analítica abordagem comunicativa/argumentação/objetivos didáticos. As análises demonstram que o papel da argumentação e os objetivos didáticos correlatos, no discurso de sala de aula, não são suficientemente claros para os sujeitos investigados. Nessa perspectiva, o equívoco dos licenciandos, em confundir explicação com argumentação, remete a necessidades formativas que devem enfatizar quais objetivos didáticos as situações argumentativas podem cumprir em sala de aula e como essas situações podem ser identificadas, promovidas, mantidas e gerenciadas pelos professores. Concluímos levantando as implicações dessa análise e perspectivas para a pesquisa e para o ensino de física e ciências.

Palavras-chave: Formação de Professores; Abordagem Comunicativa; Argumentação; Objetivos Didáticos.

\footnotetext{
* Doutor em Educação pela Faculdade de Educação da Universidade Federal de Minas Gerais (FAE-UFMG); Professor de Física da Rede Estadual de Ensino de Minas Gerais e pesquisador no Laboratório de Estudos Museu e Educação (LEME) da Faculdade de Educação da Universidade Federal de Minas Gerais (FAE-UFMG).E-mail: rodrigo_vdrumond@yahoo.com.br

** Doutora em Educação pela Universidade Pierre et Marie Curie (França); Professora Titular do Departamento de Métodos e Técnicas de Ensino da Faculdade de Educação da Universidade Federal de Minas Gerais (FAE-UFMG); Coordenadora do no Laboratório de Estudos Museu e Educação (LEME) da Faculdade de Educação da Universidade Federal de Minas Gerais (FAEUFMG). E-mail: silnascimento@ufmg.br
} 


\section{COMMUNICATIVE APPROACH, ARGUMENTATION AND DIDACTIC GOALS: A PHYSICS CLASSROOM EPISODE AS MANAGED BY A TRAINEE TEACHER}

ABSTRACT: This study presents articulated analyses of an episode of regency in a highschool physics class and its use as a teaching tool in the context of a Physics Pre-Service Teaching subject. The main goal of this work is to analyze and discuss such articulations with the support of the analytical triad communicative approach/argumentation/didactic goals. The analysis showed that the roles of argumentation and didactic goals in the science classroom discourse are unclear for the investigated undergraduate students. From this perspective, the undergraduate students' mistake in confusing explanation with argumentation demands formative actions in order to emphasize which didactic goals argumentations can satisfy in class and how such argumentations can be identified, promoted and managed by science teachers. We conclude by pointing out the implications of such analysis and perspectives for the research and for the field of physics and science teaching.

Keywords: Pre-service Teacher Education; Discourse; Argumentation; Didactic Goals.

\section{Introdução}

Estudos sobre a formação de professores têm sugerido que esse é um campo carregado de tensões e peculiaridades (TARDIF, 2002; ANDRÉ, 2002; MUNFORD et al., 2005; GOUVEIA, 2001). Na via desses estudos, perspectivas de ensino e aprendizagem aplicáveis à educação básica são, muitas vezes, desconsideradas pelos próprios formadores de professores, o que constitui uma das tensões entre a formação e a prática docente (PUTMAN; BORKO, 2000).

Reconhecemos que é importante integrar o conhecimento da prática docente na educação básica aos conhecimentos e práticas de formadores de professores, em especial na formação de docentes para as ciências e a física. Nesse sentido, situações comuns a ambos os campos de formação podem assumir centralidade para estabelecer diálogos entre a prática dos formadores de professores, de docentes em exercício e de licenciandos.

O estágio curricular de docência, obrigatório na formação inicial de professores (Lei no 11.788/2008), é um momento que pode se estender para além das fronteiras das escolas de estágio, chegando às salas de aula de formação como elemento fomentador de reflexões sobre teoria e prática. Além disso, o estágio pode ser um meio de introduzir elementos da pesquisa no contexto da prática de supervisores no campo de estágio, ou seja, o professor da educação básica em exercício. 
Consideramos que o estudo de discursos produzidos nessas situações de ensino e de aprendizagem é uma maneira frutífera para desvelar relações, continuidades e rupturas, alargando e informando nossas interpretações das interações triádicas entre duas situações de produção: alunos/estagiário/supervisor e licenciandos/estagiário/formador. Destacamos que tais interações foram assíncronas no caso aqui apresentado.

A escola sócio-histórica de psicologia sugere uma relação íntima entre pensamento e linguagem em funções cognitivas especificamente humanas, e a relação dialética entre consciência, materialidade e atividade externa (VYGOTSKY, 1986; LEONT'EV, 1978; LEONT'EV, 2004). Nessa perspectiva, um mesmo indivíduo pode falar, agir e pensar de diferentes modos quando se engaja em diferentes atividades situadas (LAVE; WENGER, 1991).

Em especial, interessa-nos o discurso emergente de situações concretas de salas de aula e suas relações com outros discursos como o currículo, a família e a comunidade e local onde a escola se situa (GOODSON, 1995). Esperamos, a partir de nossas análises, compreender a prática discursiva situada e estabelecer procedimentos discursivos didáticos capazes de serem usados como ferramentas de formação (VIEIRA, 2011).

O estudo do discurso em sala de aula tem assumido, cada vez mais, maior centralidade para a pesquisa sobre as interações, tanto da perspectiva do gerenciamento do discurso pelo professor (VIEIRA; KELLY; NASCIMENTO, 2012; VIEIRA; NASCIMENTO, 2009b), quanto da inclusão e participação dos estudantes de maneira socialmente apropriada nas práticas discursivas de sala de aula (CASTANHEIRA, 2004; KELLY, 2007).

No intuito de aprofundar essa discussão e suas consequências para a formação de professores, neste trabalho, analisamos uma situação de regência em sala de aula de física do ensino médio e sua utilização como ferramenta formadora em uma disciplina de Prática de Ensino de Física.

Nosso objetivo principal é analisar e discutir as relações e implicações de uma análise discursiva que privilegiou os elementos da tríade abordagem comunicativa/argumentação/objetivos didáticos de um episódio de estágio de docência que se constituiu como situação singular de formação em uma disciplina de Prática de Ensino de Física. 


\section{0 contexto do estudo}

As disciplinas Prática de Ensino de Física I e II (PEF I e II) constituíram, de 1994 a 2007, parte da grade curricular obrigatória na formação inicial de professores de física de várias universidades do Brasil, contendo o estágio supervisionado obrigatório (MARTINS, 2009). Ao cursarem as disciplinas, no último ano do curso, os licenciandos entravam em contato com a literatura da área de ensino de ciências e física, além de proporem atividades de planejamento para a prática docente. $\mathrm{Na}$ universidade onde o estudo foi realizado, na disciplina PEF I, de 60 horas aulas, os licenciandos realizavam o estágio curricular de observação em uma escola da rede pública de ensino, requisito parcial para aprovação na disciplina. Nesse primeiro estágio, eles acompanhavam, em, no mínimo, 30 horas, as atividades de um supervisor encarregado de orientá-los no contexto da escola onde trabalha. $\mathrm{Na}$ PEF II, os licenciandos deveriam reger duas a três turmas na escola onde realizaram a observação. A regência deveria ser realizada durante, no mínimo, 15 horas, também com o devido acompanhamento do supervisor.

Em ambas as disciplinas, eram previstas discussões sobre estágio, por meio de relatos, momento de sala de aula reservado para que cada um dos licenciandos apresentasse as vivências consideradas significativas para serem compartilhadas e problematizadas. Em vários momentos das disciplinas, o professor formador ${ }^{2}$ buscava, também, incentivar a problematização e a reflexão sobre a prática dos licenciandos com base nos relatos heterogêneos do grupo. Tais reflexões tinham como suportes teóricos artigos publicados da área e discutidos ao longo da disciplina.

A situação de ensino que trazemos para discussão neste artigo diz respeito a um desses momentos, em que o formador propõe a seguinte atividade para os licenciandos: 1) Assistir a um episódio gravado em MP4, de 30 minutos, referente a uma situação de estágio real em uma escola estadual; 2) Responder a um questionário referente ao episódio assistido composto de quatro questões abertas.

Essa atividade foi trabalhada com licenciandos em uma aula de Prática de Ensino de Física II, do curso de licenciatura em Física oferecida no período noturno. A aula teve duração aproximada de 1 hora e 30 minutos, estavam presentes 17 licenciandos com faixa etária de 21 a 30 
anos. O formador, nessa aula, foi o mesmo supervisor que acompanhou o episódio gravado em vídeo.

O formador reservou um primeiro momento da aula para a apresentação integral do episódio em vídeo, acompanhada de sua transcrição. Em um segundo momento, ele entregou um questionário referente ao episódio que deveria ser respondido pelos licenciandos e entregue ao final da aula. O objetivo do questionário era orientar a interpretação do episódio pelos licenciandos.

As questões do questionário envolveram temas anteriormente abordados em sala pelo formador: plano de ensino e recursos didáticos; discurso e argumentação em sala de aula; estrutura para análise de interações discursivas; uso de demonstrações em sala de aula; características das concepções alternativas de estudantes.

Durante o preenchimento do questionário, o formador explicou algumas questões sobre as quais os licenciandos apresentaram dúvidas. $\mathrm{E}$, ao final da aula, ele recolheu os questionários e fez uma discussão geral das questões e de algumas das respostas. Neste artigo, concentraremos nossas análises nas relações entre o episódio de ensino em vídeo e duas questões específicas do questionário:

- Você avalia algum trecho do episódio assistido como argumentativo? Sob qual critério baseia-se a sua avaliação?

- Associe a cada abordagem comunicativa (interativo/dialógico, interativo/de autoridade, não interativo/dialógico, não interativo/de autoridade) um possível propósito pedagógico do professor observado (e.g. sondar pontos de vista dos estudantes, introduzir um problema, trazer o ponto de vista da ciência, marcar ideias-chave, etc.). Justifique as suas associações.

Enfim, elegemos para análise o episódio em vídeo e as respostas dos licenciandos para as duas questões em função de nosso objetivo principal de caracterizar, discursivamente, a prática de um estagiário em um episódio real de regência e a sua utilização como instrumento para a formação de professores de física.

Nossa opção em privilegiar essa abordagem se fundamenta na importância do gerenciamento das situações discursivas em sala de aula segundo um ritmo discursivo, em que determinados objetivos didáticos 
são cumpridos de acordo com o controle do professor sobre as variações no discurso produzido. Porém, reconhecemos que, no contexto de formação de professores, não é óbvio para os licenciandos compreenderem os modos pelos quais certos discursos, em sala de aula, são classificados, gerenciados e relacionados a determinados objetivos didáticos (VIEIRA; KELLY; NASCIMENTO, 2012). Disso se justifica o nosso recorte em focar as duas questões do questionário explicitadas anteriormente, pois elas dizem respeito explicitamente ao discurso de sala de aula do episódio assistido.

$\mathrm{Na}$ próxima seção, vamos caracterizar o contexto do episódio assistido, para, em seguida, explicitarmos os objetivos secundários deste trabalho em função do nosso enfoque discursivo.

\section{0 episódio de regência é assistido pelos licenciandos}

Na ocasião do episódio, ocorrido em uma turma de segundo ano do ensino médio noturno de uma escola estadual, em bairro de classe média, estavam presentes, em sala, cerca de 30 alunos (faixa etária entre 18 e 30 anos), a maioria do sexo feminino. O estagiário, Carlo, e o supervisor de estágio estabeleceram a Física Térmica, sob um enfoque qualitativo, como conteúdo do planejamento da sequência de ensino de regência. O supervisor disponibilizou três aulas para o estagiário desenvolver a sua sequência de ensino.

A comunidade atendida nessa escola era constituída por alunos de classes sociais menos favorecidas financeiramente, e que, em geral, moravam em aglomerados vizinhos à escola e trabalhavam durante todo o dia no comércio das redondezas.

O episódio filmado envolveu a correção de exercícios sobre calorimetria, solucionados em casa a partir da demanda do estagiário na aula anterior. Selecionamos o episódio em função do planejamento de uma demonstração ${ }^{3}$ ao final da aula e da intenção do formador em utilizá-lo, posteriormente, como instrumento de formação no âmbito da disciplina de Prática de Ensino de Física II. Nesse episódio, estavam presentes dois estagiários, o regente (Carlo) e o observador (que era regente em outra turma da mesma escola), além do supervisor, que também estava na posição de observador, fazendo ocasionalmente pequenas intervenções. 
De acordo com o planejamento de Carlo, a demonstração apresentada ao final do episódio tinha o objetivo de retomar e confirmar conceitos trabalhados anteriormente.

\section{Referenciais teóricos: discurso e argumentação em sala de aula}

O discurso em sala de aula tem-se tornado, cada vez mais, objeto de estudo em pesquisas de filiação sócio-histórica que remontam aos trabalhos de Vygotsky (1986) e Bakhtin (1986). Estudos nessa área compreendem que os significados construídos e compartilhados em contextos de ensino e aprendizagem em salas de aula de ciências mostram-se largamente dependentes das dinâmicas discursivas que se estabelecem em tais contextos (LEMKE, 1990). Assim, tornou-se óbvia a necessidade de mapear essas dinâmicas, bem como propor grades analíticas em função do levantamento de suas especificidades. Em resposta às demandas, o campo de pesquisa da área tem-se expandido rapidamente, e, hoje, dispomos de razoável arcabouço de estruturas e categorias analíticas para lidar com a diversidade discursiva de sala de aula (KELLY, 2007).

Inseridos nesse contexto, Mortimer e Scott (2003) apresentam uma estrutura analítica inspirada na teoria sociocultural (WERTSCH, 1991) que tem sido utilizada como uma ferramenta para compreensão das relações e tensões entre as abordagens comunicativas dialógicas e de autoridade no ensino de ciências. A estrutura possibilita aos professores aumentarem a consciência de suas próprias práticas, além de propiciar a compreensão da necessidade de uma autêntica abordagem dialógica no ensino de ciências. Entretanto, a estrutura não foi desenvolvida para esclarecer distinções entre, por exemplo, uma argumentação e uma explicação. Consideramos que é importante estudar as nuanças dentro das categorias que essa estrutura propõe, isto é, como a abordagem dialógica proposta pelos autores se relaciona com discursos argumentativos e não argumentativos.

Assim, propomos uma complementação para lidarmos com diferenças entre argumentação e explicação, duas situações justificatórias cujas qualidades e contribuições para o ensino e aprendizagem são largamente reconhecidas pela literatura da área (JIMENEZ-ALEIXANDRE; EDURAN, 2008; OGBORN et al., 1996). Essas situações são objeto de 
nossas análises e, portanto, distinções entre ambas devem ser estabelecidas, pois, como veremos, cada uma delas pode cumprir objetivos didáticos diferenciados.

Em trabalho anterior (VIEIRA; NASCIMENTO, 2009a), consideramos a argumentação como essencialmente polissêmica e traçamos uma distinção entre argumentação e explicação com base na literatura (BILLIG, 1996; CHARAUDEAU; MAINGUENEAU, 2004; PLANTIN, 2005). A partir dessa distinção, propusemos dois critérios principais para as situações argumentativas: contraposição de ideias (opiniões) e justificações recíprocas. Nesse mesmo trabalho, a partir de trechos de situações discursivas de sala de aula, mostramos como os critérios se mostram operacionais para identificar argumentações e distingui-las de outras situações discursivas.

Tomando as diferenças entre argumentação, podemos relacionálas com diferentes abordagens comunicativas nas quais é importante notar que "o conceito de abordagem comunicativa fornece a perspectiva de como o professor trabalha com os estudantes para desenvolver significados na sala de aula (MORTIMER et al., 2008, p.68).

Esses autores identificaram quatro classes fundamentais de abordagem comunicativa, que podem ser definidas pela caracterização da fala entre professor e alunos ao longo de duas dimensões: dialógica - de autoridade e interativa - não interativa. Essas classes são definidas pelos autores da seguinte maneira:

Interativa/dialógica: o professor e os estudantes exploram ideias, gerando dessa forma novos significados, através da proposta de questões e a partir da consideração de diversos pontos de vista, tanto dos estudantes quanto do professor.

Não interativa/dialógica: o professor considera vários pontos de vista, mas esses se restringem apenas à sua fala; o professor trabalha e explora as várias perspectivas que surgem desses pontos de vista.

Interativa/de autoridade: o professor objetiva alcançar um ponto de vista específico através de uma sequência de apresentação de questões que são respondidas pelos alunos.

Não interativa/de autoridade: o professor apresenta somente um ponto de vista específico (MORTIMER et al., 2008, p.39). (Tradução do autor).

Primeiramente, é evidente que a argumentação, da maneira como a definimos, deve associar-se a uma abordagem comunicativa dialó- 
gica/interativa. A polissemia inerente à argumentação e a consideração mútua de opiniões e justificativas recíprocas são aspectos que apoiam a sua associação com a abordagem comunicativa dialógica/interativa. $\mathrm{Ou}$ seja, o professor, ao assumir essa abordagem comunicativa, abre o discurso para que os alunos possam contribuir com diferentes pontos de vista, além de poderem apreciar e criticar os pontos de vista alheios, em uma autêntica criação de palavras e contrapalavras (BILLIG, 1996). No caso dessa abordagem ser identificada, seriam necessários ainda critérios complementares para distinguir uma argumentação de uma explicação. Esses critérios seriam justamente aqueles que propusemos anteriormente para identificarmos a argumentação: contraposição de ideias e justificativas recíprocas.

Quanto à possibilidade de a argumentação se manifestar nas demais abordagens comunicativas, avaliamos que, conforme a definição que utilizamos, e especialmente em função de seu caráter persuasivo e de competição, não podemos traçar a associação da argumentação com as abordagens comunicativas restantes. Se o discurso é de autoridade, tanto na dimensão interativa quanto não interativa, o professor fixa a atenção da turma em apenas um ponto de vista, geralmente o da ciência. Evidentemente, isso nos retira do campo da argumentação, que pressupõe a consideração mútua de diferentes pontos de vista (opiniões). Além disso, também não podemos associar a argumentação a uma abordagem comunicativa dialógica/não interativa. Nesse caso, há a polissemia na fala de um mesmo sujeito, geralmente o professor, na qual diferentes pontos de vista, que podem, inclusive, ser contraditórios, são explicitados e colocados no plano social de sala de aula. Tais pontos de vista não estão em competição, pois são formulados por um mesmo sujeito. Assim, por critérios de coerência, podemos avaliar que não há disputa entre esses pontos de vista, uma vez que um deles é assumido pelo professor como o correto. Paralelamente, se considerarmos a característica persuasiva inerente a toda argumentação, nessa dimensão, pode não emergir uma situação argumentativa de forma direta com o objetivo de mudar o ponto de vista do interlocutor.

Resta-nos questionar se a explicação pode ser desenvolvida em uma abordagem dialógica/interativa. Uma análise cuidadosa a esse respeito foge dos propósitos deste artigo. Vamos assumir que as explicações em sala de aula podem cobrir todas as quatro dimensões da abordagem 
comunicativa e, complementarmente, que a argumentação somente pode existir em uma abordagem dialógica/interativa. Isso, se considerarmos, é importante salientar, que os argumentos em sala de aula são sempre dirigidos a um público real.

Considerando essa discussão, mostraremos, a partir de análises articuladas de um trecho discursivo do episódio de regência de Carlo e a sua aplicação em situação de formação, que a percepção desse trecho como argumentativo pelos licenciandos diverge da nossa própria avaliação pautada nos critérios que propusemos para identificar as situações argumentativas: abordagem dialógica/interativa, contraposição de ideias e justificações recíprocas.

Com essa análise, mostraremos que não há nada de óbvio em reconhecer situações argumentativas e que o uso do vídeo em situações de formação é um recurso formativo valioso para promover reflexões acerca da prática discursiva em sala de aula, a partir de categorias e estruturas teóricas específicas para essa finalidade.

Mostraremos também que, apesar de avaliarmos que o trecho em foco não é argumentativo, o discurso nesse contexto de produção não deve ser desqualificado por isso, pois ele cumpre um objetivo bastante claro e coerente dentro da sequência temporal do episódio considerado. Isso nos levará a outra discussão, a saber, entre as relações dos objetivos didáticos e as abordagens comunicativas que o professor promove em sala de aula.

\section{Análises e resultados}

Retomamos nosso objetivo principal de analisar e discutir um episódio de regência e sua utilização como instrumento de formação. Para contemplá-lo, fizemos uma análise articulada do episódio de regência e da situação de formação, a partir da qual foi possível também contemplar os seguintes objetivos secundários:

- Contrapor critérios para identificar situações argumentativas com as avaliações dos licenciandos sobre o episódio assistido;

- Avaliar a coerência dos licenciandos em relacionar abordagem comunicativa e objetivos didáticos; 
- Discutir o uso do vídeo como instrumento para a formação.

Visando a atender a esses objetivos, vamos articular nossas análises discursivas do vídeo às respostas dos licenciandos às duas questões do questionário.

\section{Por que o episódio não é argumentativo?}

Ao analisarmos, na íntegra, todo o episódio apresentado em vídeo, não identificamos a presença de uma argumentação enquanto associação entre opiniões em contraposição e justificações recíprocas. Entretanto, após assistirem ao episódio, todos os licenciandos respondentes à questão apontaram o trecho correspondente à atividade da demonstração como argumentativo.

Avaliamos o discurso produzido nesse trecho de autoridade/ interativo com a construção de uma explicação coletiva para o fenômeno observado, e um forte gerenciamento do estagiário, que faz perguntas e seleciona, ignora, rejeita e marca justificativas e respostas. A partir das contribuições dos alunos, ele as reelabora e as (re)organiza em sua fala e com isso constrói cadeias de causalidade para explicar o fenômeno observado. O excerto 1 ilustra alguns dos procedimentos discursivos do estagiário.

\section{Excerto 1: Trecho de transcrição do episódio}

11 - Carlo: ... pra que vocês acham que serve a luz ali embaixo? (vários alunos falam ao mesmo tempo) [estagiário faz uma pergunta]

12 - A3: Pra fornecer calor.

13 - Carlo: Ó, alguém falou uma coisa boa ali atrás, aqui, uma coisa assim, explodiu ó, quase deu a resposta total da pergunta ali ó, ele falou que a luz serve pra fornecer calor. [estagiário seleciona e marca uma resposta] 14 - A1: E serve pra iluminar. (vários alunos dão risadas, estagiário fica desconcertado).

15 - Carlo: Tá, (estagiário dá uma risada), então tá. [estagiário ignora a resposta]

16-A2: É isso aí mesmo que ela falou. (vários alunos falam ao mesmo tempo).

$17-$ A1: Serve pra subir e descer.

18 - Carlo: Forneceu calor, energia, calor é uma forma de energia, tá transferindo energia, então tá, forneceu calor, o que vai acontecer com a gororoba ali 
dentro? [estagiário ignora as respostas anteriores dos alunos A2 e A1 e inicia a construção de uma cadeia de causalidade a partir das contribuições anteriores dos alunos e da elaboração de uma pergunta no final da sua fala]

19-A?: A gororoba?

20 - A4: Vai dilatar...

21 - Carlo: (apontando pro aluno A4) Como é que é? Ela vai o quê? Que que você falou antes? Vai esquentar e |A?: Vai dilatar| (vários alunos falam ao mesmo tempo e alguns dizem que vai dilatar) ó, outra coisa boa aí, ó. [estagiário seleciona e marca uma resposta]

22 - A4: É isso mesmo, ela vai expandir porque vai dilatar...

23 - Carlo: É, então ela vai receber calor que você falou, vai aumentar a temperatura e ela falou que vai dilatar, não vai? Quando alguma coisa esquenta não vai dilatar? Que acontece quando alguma coisa dilata? Alguém lembra? Eu cheguei a comentar isso. [estagiário constrói uma cadeia de causalidade, ainda incompleta, a partir das contribuições anteriores, ao final da qual lança uma pergunta]

\footnotetext{
Legendas:

A1 - aluno 1; A2 - aluno 2; A3 - aluno 3; etc.

A? - aluno não identificado.

(Expressões entre parênteses) - comentários do transcritor referentes ao contexto observado na gravação em vídeo.

|Expressões entre barras | - falas simultâneas.

Expressões entre colchetes e sublinhadas] - procedimentos discursivos do estagiário.
}

Conforme se percebe, pela análise, o estagiário não incita a competição ou pede as credenciais das afirmações que considera equivocadas, o que poderia favorecer uma argumentação. Desse modo, o discurso tem um fio condutor muito bem estabelecido pelo estagiário, que é o da voz da ciência: as afirmações dos alunos em desacordo com essa voz são ignoradas ou rejeitadas. Estabelece-se um jogo discursivo em que os alunos buscam dizer o que o estagiário espera, e este, na sua posição institucional de assimetria, constrói cadeias explicativas a partir das contribuições "corretas" dos alunos. Essas cadeias vão-se expandindo durante as interações e, por fim chegam a uma versão mais elaborada, ao final do episódio apresentada.

É importante salientar que o trecho da demonstração envolve, ao longo do seu curso, a apresentação de afirmações e justificativas, mas delas não surgem contrapontos justificados. Quer dizer, não há argumentação porque não há contraposição, não há, de fato, contra-argumentos no sentido de contra-opinião com justificativa. 
Essas características discursivas da abordagem comunicativa de autoridade/interativo podem ser relacionadas especificamente ao propósito de Carlo em consolidar e confirmar pontos de vista já trabalhados anteriormente, o que é evidenciado em sua fala no trecho de transcrição apresentado ("Alguém lembra?", "Eu cheguei a comentar isso", linha 23).

\section{0 que avaliam os licenciandos sobre a argumentação no episódio?}

Com relação à situação de formação e retomando as respostas para a questão - "Você avalia algum trecho do episódio assistido como argumentativo? Sob qual critério baseia-se a sua avaliação?":

Houve um silêncio generalizado dos licenciandos, embora a maioria deles tenha respondido a todas as outras questões do questionário. Para as poucas respostas à questão sobre argumentação (apenas quatro dos 17 licenciandos responderam), houve unanimidade em considerar o trecho da demonstração como argumentativo.

Além disso, esses quatro licenciandos não apresentaram critérios para identificar as situações argumentativas (abordagem dialógica/interativa, contraposição de ideias e justificações recíprocas). As respostas demonstram a confusão feita pelos licenciandos entre explicar e argumentar e entre a função do argumento na sequência, como se percebe na resposta a seguir: "Sim, na hora que ele vai explicar a demonstração, ele usa uma série de argumentos pra explicar o fenômeno em questão" (Licenciando 8).

Esses resultados são indícios da dificuldade em distinguir argumentos, argumentação e explicação. Complementarmente, isso é indício de que os licenciandos não perceberam, também, o objetivo do estagiário, naquela fase do episódio discursivo, de consolidar e confirmar pontos de vista trabalhados anteriormente. Tal fato situa o trecho em uma abordagem comunicativa de autoridade e interativa, incompatível com uma situação argumentativa. Esse ponto será mais desenvolvido nas seções seguintes. 


\section{A abordagem comunicativa e a satisfação de objetivos didáticos}

Em relação à segunda questão, os licenciandos foram influenciados pelo formador, que, frente à possível dificuldade em interpretar a questão, forneceu uma primeira associação: sondar pontos de vista dos estudantes - dialógico /interativo.

É importante notar que certas abordagens comunicativas dificultam a satisfação de determinados objetivos, ao passo que possibilitam a realização de outros. Podemos exemplificar a restrição se lembrarmos do objetivo de sondar pontos de vista dos estudantes. Nesse caso, a abordagem comunicativa de autoridade/não interativa claramente não pode ser associada ao cumprimento desse objetivo didático.

Tendo em mente tais considerações como exemplo, discutiremos as lacunas e incoerências de uma resposta: "fazer exercícios numéricos - dialógico/não interativo; passar um conceito científico mais fácil de discutir - de autoridade/interativo" (Licenciando 1).

Ainda que tenhamos discutido longamente esse tema, os licenciandos apresentaram lacunas para associar um objetivo didático à abordagem comunicativa. Qual abordagem comunicativa viável para o objetivo didático de resolver exercícios numéricos? $\mathrm{Na}$ resposta do Licenciando 1 , podemos inferir a confusão entre diálogo e dialogia. O fato de o professor promover alternância de interlocutores não garante que o discurso seja dialógico. Logo, uma situação de sala de aula de discussão sobre um exercício numérico, estratégia de ensino importante e muito presente nas aulas expositivas de física, não pode ter uma abordagem dialógica/não interativa. Os possíveis algoritmos de solução de uma situação física numérica exigem um ponto de vista teórico bem claro. E se essa situação discursiva é não interativa, está implícita a exposição de um mesmo interlocutor de quais pontos de vista? Logo, essa associação é igualmente incoerente com uma situação de resolução de exercício em física.

O mesmo licenciando associa o segundo objetivo didático de "passar um conceito científico mais fácil de discutir" à abordagem comunicativa de autoridade/interativo. O que ele pode considerar um "conceito mais fácil de discutir" no ensino médio? Temos indícios, nesse caso, do discurso da formação inicial do professor de física em que há a crença de existirem conceitos físicos que são mais fáceis de transmitir que outros. $O$ que é fácil de discutir, mas que precisa apresentar uma abordagem comu- 
nicativa de autoridade? O que o licenciando entende por "passar um conceito"? Será que os alunos entram em um jogo discursivo interativo em que somente um ponto de vista será considerado? Muitas vezes, estabelecem-se, em sala de aula, cadeias interativas, no modelo de iniciação-resposta-feedback, direcionadas para o ponto de vista da ciência, importantes para os momentos de síntese e reformulação de conceitos. Podemos nos questionar sobre a lacuna de questionamento na formação inicial da elaboração dos objetivos didáticos, e a lacuna conceitual presente nessa resposta pode ter origem na própria disciplina ministrada.

É importante observar que a maioria dos licenciandos não foi capaz de associar os objetivos didáticos à abordagem comunicativa discutida em sala de aula. Naturalmente, podemos questionar se a forma de trabalhar com o quadro teórico de Mortimer e Scott (2003) e o comando à questão foram adequados. Outra questão pertinente diante da ausência de dados é a dificuldade para um licenciando, de forma não situada, atribuir um objetivo didático a uma abordagem comunicativa. As respostas dos licenciandos nos informam pouco sobre a relação que eles estabeleceram nesse caso.

Se o discurso é de autoridade, tanto na dimensão interativa quanto não interativa, o professor visa à sua fala na explicitação de um ponto de vista, geralmente o da ciência. Isso nos coloca no campo da explicação, no qual as trocas discursivas complementam uma mesma opinião. Já se a abordagem comunicativa é dialógica e não interativa, é possível ser associada à explicação. Nesse caso, a polissemia na fala de um mesmo sujeito implica a definição de diferentes pontos de vista, muitas vezes contraditórios, que não evolui para uma sequência explicativa per si. $\mathrm{O}$ enunciador vai selecionar sucessivamente pontos de vista para enunciar a explicação e pode mesmo evoluir na enunciação para uma argumentação! Enfim, se o discurso é dialógico e interativo, a explicação de diferentes pontos de vista pode emergir coletivamente enunciada por diferentes sujeitos que compartilham os mesmos conhecimentos. Se há um movimento de persuasão dos diferentes pontos de vista, estamos diante de várias explicações que podem evoluir paralelamente para a emergência de uma sequência de argumentação! 


\section{Discussão dos resultados}

\section{Abordagem comunicativa, argumentação e objetivos didáticos: quais as relações?}

As respostas às questões do questionário apresentadas e discutidas anteriormente, quando interpretadas à luz dos resultados de análise, são indícios de uma situação problemática. Primeiramente, ao silenciarem sobre a questão da argumentação ou indicando o trecho da demonstração como argumentativo e não explicativo, os licenciandos demonstraram não distinguirem a natureza dessas situações discursivas e, consequentemente, os objetivos que elas podem cumprir em sequências de ensino. A resposta à questão que indagava sobre a presença da argumentação no episódio, apresentada a seguir, exemplifica como os licenciandos confundiram argumentação com explicação: "Sim, durante a explicação do fenômeno dentro da demonstração" (Licenciando 7).

Em um sentido mais amplo, a análise conjunta das duas questões nos leva a questionar se, com isso, os licenciandos também não estariam perdendo de vista o fato de o estagiário estar consolidando, no momento da demonstração, pontos de vista já trabalhados anteriormente, por meio de uma abordagem comunicativa de autoridade/interativa. Quer dizer, os licenciandos não estariam perdendo de vista a relação de coerência entre a abordagem comunicativa e o objetivo didático de consolidar conceitos apresentados? Inclusive, antes de trabalhar a demonstração propriamente dita, Carlo anuncia que: "Isso [a demonstração] tem a ver com tudo que a gente já viu aqui no curso, calor, transferência de energia, temperatura $[\ldots] "$.

Com essas palavras, Carlo antecipa que o momento é de falar e pensar sob o ponto de vista da ciência que foi ensinada anteriormente. As respostas dos licenciandos que consideraram o trecho da demonstração como argumentativo são indícios de que eles apresentam dificuldades em reconhecer que, no contexto da demonstração, Carlo pretende focar no ponto de vista da ciência (abordagem comunicativa de autoridade/interativa).

Podemos questionar se a sucessão de trocas discursivas enunciadas por diferentes interlocutores (o diálogo), associada ao fato de que cadeias causais são construídas seriam elementos que revestem o trecho considerado de uma certa aparência argumentativa para os licenciandos. 
Podemos questionar ainda se, de fato, os licenciandos apresentam um domínio da relação de coerência entre abordagem comunicativa e objetivos didáticos. Esse seria apenas um domínio de ordem mecânica e abstrata? Consideramos que os nossos resultados apontam para uma resposta positiva para essa indagação.

\section{Implicações para a formação}

Reforçamos que as análises foram pautadas na articulação de elementos de duas situações de produção assíncronas: 1) A situação de regência, em que estiveram presentes interações entre alunos-estagiáriosupervisor, mediadas pelo uso do aparato experimental "Lâmpada de Lava"; 2) A situação de formação cujas interações se deram entre licenciandos-formador, mediadas por um questionário aplicado e a exibição de um episódio em vídeo com sua respectiva transcrição. As análises assíncronas das duas situações de produção foram complementares, contribuindo para promover reflexões e tomadas de consciências dos licenciandos e do formador no espaço de uma disciplina de Prática de Ensino de Física.

A instrumentalização dos licenciandos é um aspecto complementar aliado à compreensão da importância do papel do discurso em sala de aula. Com a instrumentalização, os licenciandos podem ganhar desenvoltura em conduzir o discurso, gerenciando e adequando o seu ritmo discursivo aos objetivos previamente traçados em seu planejamento.

Os licenciandos certamente podem adquirir essa desenvoltura de outras maneiras, como observar a prática de colegas em atividades formativas especificamente destinadas para essa finalidade, como a prática analisada neste trabalho. A formação inicial precisa abordar o gerenciamento do discurso em sala de aula, em que todos os recursos disponíveis devem ser mobilizados para favorecer tomadas de consciência. Nesse sentido, o uso do vídeo aliado a estruturas e categorias de análise são recursos que consideramos importantes e necessários.

As discussões e os resultados apresentados nos levam a concluir que os licenciandos demonstraram propriedade em explicitar com razoável coerência as relações entre abordagem comunicativa e objetivos didá- 
ticos em situação hipotética, abstrata. Entretanto, mesmo em uma pequena amostra sobre a segunda questão, houve dificuldade na identificação de uma sequência argumentativa aplicando nossos critérios. Isso nos motivou a levantar a hipótese de que os licenciandos perderam de vista que o trecho considerado cumpria um objetivo didático em uma fase do episódio e que dificilmente poderia ser satisfeito por uma situação argumentativa: retomar, confirmar e consolidar conceitos discutidos anteriormente.

O levantamento dessa hipótese nos remeteu diretamente a outra, a saber, se o domínio teórico entre a abordagem comunicativa e os objetivos didáticos, conforme explicitado nas respostas dos licenciandos, não necessariamente reflete o domínio de perceber as relações estabelecidas e desenvolvidas no plano discursivo concreto de sala de aula. Salientamos que, para o levantamento dessas hipóteses e questões, foram fundamentais as relações que estabelecemos entre o quadro teórico que propusemos para identificar situações argumentativas (VIEIRA; NASCIMENTO, 2009a) e as dimensões de abordagem comunicativa propostas por Mortimer e Scott (2003).

Nessa perspectiva, o equívoco dos licenciandos em confundir explicação com argumentação remete a necessidades formativas que devem enfatizar quais objetivos didáticos as situações argumentativas podem cumprir em sala de aula e como tais situações podem ser identificadas, promovidas, mantidas e gerenciadas pelos professores. Essa problemática nos levou ao estudo dos Procedimentos Discursivos Didáticos (PDD) dos professores em orientações discursivas argumentativas, explicativas, narrativas, descritivas e injuntivas. Esse quadro teórico e analítico é apresentado em detalhes em Vieira, Kelly e Nascimento (2012) e em Vieira (2011).

Outro ponto problemático foi o silêncio da maioria dos licenciandos frente à questão sobre argumentação. Tais resultados podem até mesmo soar contraditórios se lembrarmos que a palavra argumentação está presente no cotidiano de todos e tem também presença marcante em pesquisas recentes conduzidas em sala de aula (JIMENEZ-ALEIXANDRE; EDURAN, 2008).

A aparente contradição se dissolve se consideramos que o uso comum de uma palavra nem sempre reflete o significado que a ciência, ou um campo da ciência, lhe atribui. Isso ocorre e é amplamente conhecido pela pesquisa em ensino de ciências quanto às diferenças entre as chama- 
das concepções de senso comum dos alunos da educação básica e as concepções científicas (PEDUZZI; ZYLBERSTAJN; MOREIRA, 1992).

Situadas em cada uma dessas esferas de significados, palavras como "pressão" ou "calor" apresentam significados muitas vezes radicalmente diferentes. Entendemos que o mesmo ocorre com a palavra "argumentação" se consideramos os seus significados científicos e aqueles que os licenciandos e professores de ciências lhe atribuem. Tal fato se torna premente, principalmente se lembrarmos do distanciamento desses sujeitos em relação ao campo da linguística, da análise do discurso e da psicologia, o que pode ser um fator de inibição frente a questões que demandem a explicitação de conhecimentos desse tipo.

Quanto ao papel do registro em vídeo, ele se mostrou, em associação com as duas questões analisadas, um instrumento de formação capaz de mediar a teoria com a prática concreta. Assim, eles funcionaram como mediadores entre o mundo das ideias (das categorias de abordagem comunicativa e da argumentação) com o mundo real (da prática concreta em sala de aula).

Nossa prática como formadores de professores nos tem evidenciado que os licenciandos sentem dificuldades em utilizar as teorias pedagógicas para interpretar situações de sala de aula, frequentemente reclamando que "a teoria não funciona na prática". Evidentemente, a ausência de mediadores entre esses dois mundos no espaço de uma disciplina como a Prática de Ensino de Física é um fator que reforça esse fato. Portanto, devemos, cada vez mais, estabelecer essas pontes mediadoras em nossas aulas de formação de professores, para identificarmos as lacunas e inconsistências, para, então, discuti-las e superá-las. O uso do vídeo é uma das maneiras frutíferas de se estabelecer essas pontes, conforme nos aponta Carvalho e Gil-Pérez (2001).

As análises e os resultados apresentados contribuem para a construção de imagens mais próximas da prática real dos professores, cujas reais circunstâncias têm sido, muitas vezes, desconsideradas pelos designers de currículos (GOODSON, 1995), que apresentam prescrições intangíveis dadas as condições concretas da prática da maioria dos professores de física e ciências no Brasil. Apesar da relevância de compreendermos melhor a prática concreta, ainda há um longo percurso de pesquisa para integrar análises históricas da prática dos professores e da construção de currículos (AYRES; SELLES, 2012) e o atual cenário de ensino de física 
e ciências no Brasil. Além de saber o "que é", por meio de análise das práticas discursivas de sala de aula, necessitamos também saber "como" chegamos historicamente "ao que é". Um diálogo mais frutífero entre esses dois níveis e campos de análise é necessário e urgente para a pesquisa em ensino de física e ciências.

\section{NOTAS}

1 Apoio CNPq, CAPES, FAPEMIG.

2 No restante deste artigo, o professor formador do ensino superior será chamado apenas de formador.

3 A demonstração foi baseada no funcionamento da "Lâmpada de Lava". Este é um dispositivo em formato cilíndrico em que há duas substâncias líquidas de cores e proporções volumétricas diferentes e com densidades próximas. Na base do dispositivo, existe uma lâmpada incandescente que aquece a substância mais densa, que, aquecida, dilata-se e diminui sua densidade em relação à da outra substância. $\mathrm{O}$ resultado é o surgimento de um movimento ascendente e descendente das substâncias, oriundo da variação de densidade e da troca de calor por convecção.

\section{REFERÊNCIAS}

ANDRÉ, M. E. A. (Org.). Formação de professores no Brasil (1990-1998). Brasília: MEC/InepComped, 2002.

AYRES, A. C. M.; SELLES, S. E. História da formação de professores: Tentativas de diálogos com a disciplina escolar ciências no ensino fundamental. Ensaio: Pesquisa em Educação em Ciências, Belo Horizonte, v.14, n.2, p.95-107, 2012.

BAKHTIN, M. Speech genres and other late essays. Austin: University of Texas Press, 1986. BILLIG, M. Arguing and thinking: a rhetorical approach to social psychology. 2ed. Cambridge: Cambridge University Press, 1996.

CARVALHO, A. M. P.; GIL-PÉREZ, D. Formação de professores de ciências: tendências e inovações. 7ed. São Paulo: Cortez Editora, 2001.

CASTANHEIRA, M. L. Aprendiragem contextualizada: discurso e inclusão na sala de aula. Belo Horizonte: Ceale; Autêntica, 2004.

CHARAudeaU, P.; MAINGUENEAU, D. Dicionário de análise do discurso. São Paulo: Contexto, 2004.

GOODSON, I. F. Currículo: teoria e história. Petrópolis: Vozes, 1995.

GOUVEIA, M. S. F. Pesquisa e prática pedagógica na formação do professor: como entendê-la? Pro-posiçōes, Campinas, v.12, n.1, p.27-46, 2001. 
JIMÉNEZ-ALEIXANDRE, M. P.; ERDURAN, S. Argumentation in science education: an overview. In: ERDURAN, S.; JIMÉNEZ-ALEIXANDRE, M. P. (Eds.). Argumentation in science education: recent developments and future directions. Dordrecht: Springer, 2008. p.3-27.

KELLY, G. J. Discourse in science classrooms. In: ABELL, S.; LEDERMAN, N. (Eds.). Handbook of research on science education. Lawrence Erlbaum Associates, 2007. p.443-470.

LAVE, J.; WENGER, E. Situated learning: legitimate peripheral participation. Cambridge: Cambridge University Press, 1991.

LEMKE, J. L. Talking science: language, learning and values. Norwood: Ablex, 1990.

LEONT'EV, A. N. Activity, consciousness, and personality. Englewood Cliffs: Prentice-Hall, 1978.

LEONTI'EV, A. N. O desenvolvimento do psiquismo. São Paulo: Centauro, 2004.

MARTINS, A. F. Estágio supervisionado em física: o pulso ainda pulsa... Revista Brasileira de Ensino de Física, São Paulo, v.31 n.3, p.3.402, 2009. Disponível em:

http://www.scielo.br/pdf/rbef/v31n3/a06v31n3.pdf . Acesso em: 14 ago. 2013.

MORTIMER, E. F.; SCOTT, P. Meaning making in secondary science classrooms. Philadelphia: Open University, 2003.

MUNFORD, D.; LOPES, M. G.; TAVARES, F. P.; VIEIRA, R. D. Práticas discursivas e o ensino-aprendizagem do professor de ciências: tecendo relações entre argumentação e objetivos pedagógicos na formação inicial. Atas do V ENPEC, Bauru, São Paulo, 2005. CROM.

OGBORN, J.; KRESS, G.; MARTINS, I.; MCGILLICUDDY, K. Explaining science in the classroom. Buckingham: Open University Press, 1996.

PEDUZZI, L. O.; ZYLBERSZTAJN, A.; MOREIRA, M. A. As concepções espontâneas, a resolução de problemas e a história da ciência numa sequência de conteúdos em mecânica: o referencial teórico e a receptividade de estudantes universitários à abordagem histórica da relação força e movimento. Revista Brasileira de Ensino de Física, São Paulo, v.14, n.4, p.239-246, 1992.

PLANTIN, C. A argumentação: história, teorias, perspectivas. São Paulo: Parábola Editorial, 2008.

TARDIF, M. Saberes docentes e formação profissional. 6ed. Petrópolis: Vozes, 2002.

VIEIRA, R. D. Discurso em salas de aula de ciências: uma estrutura de análise baseada na teoria da atividade, sociolinguística e linguística textual. 138f. Tese (Doutorado em Educação) - Faculdade de Educação, Universidade Federal de Minas Geais, Belo Horizonte, 2011.

VIEIRA, R. D.; KELLY, G. J.; NASCIMENTO, S. S. An activity theory-based framework for the study of discourse in science classrooms. Ensaio: Pesquisa em Educação em Ciências, Belo horizonte, v.14, n.2, p.13-46, 2012.

VIEIRA, R. D.; NASCIMENTO, S. S. A argumentação no discurso de um professor e seus estudantes sobre um tópico de mecânica newtoniana. Caderno Brasileiro de Ensino de Física, Florianópolis, v.24, n.2, p.174-193, 2007.

VIEIRA, R. D.; NASCIMENTO, S. S. Uma proposta de critérios marcadores para identificação de situações argumentativas em salas de aula de ciências. Caderno Brasileiro de Ensino de Física, Florianópolis, v.26, n.1, p.81-102, 2009a.

VIEIRA, R. D.; NASCIMENTO, S. S. Uma visão integrada dos procedimentos discur- 
sivos didáticos de um formador em situações argumentativas de sala de aula. Ciência \& Educação, Bauru, v.15, n.3, p.1-15, 2009b.

VYGOTSKY, L. S. Thought and language. Cambridge, MA: The MIT Press, 1986.

WERTSCH, J. V. Voices of the mind: a sociocultural approach to mediated action. Cambridge, Mass.: Harvard University Press, 1991.

Recebido em: 28/11/2012

Aprovado em: 09/09/2013

Contato:

Faculdade de Educação Universidade Federal de Minas Gerais Avenida Antônio Carlos, 6627 CEP $31270-901$

Belo Horizonte | MG | Brasil 